Article

\title{
Social Support for Digital Inclusion: Towards a Typology of Social Support Patterns
}

\author{
Axelle Asmar ${ }^{1, *}$, Leo van Audenhove ${ }^{1,2}$ and Ilse Mariën ${ }^{1}$ \\ 1 iMEC-SMIT, Vrije Universiteit Brussel, 1050 Etterbeek, Belgium; E-Mails: axelle.asmar@vub.be (A.A.), \\ leo.van.audenhove@vub.be (L.v.A.), ilse.marien@vub.be (I.M.) \\ ${ }^{2}$ CoLAB, University of the Western Cape, Cape Town, South Africa \\ * Corresponding author
}

Submitted: 10 November 2019 | Accepted: 8 January 2020 | Published: 14 May 2020

\begin{abstract}
This article contributes to a better understanding of patterns of social support in relation to digital inequalities. Based on an extensive qualitative study, the diversity of support networks and supports seeking patterns are unveiled. A typology of six patterns of help-seeking is presented and described: the support-deprived, the community-supported, the supported through substitution, the network-supported, the vicarious learners, and the self-supported. The article also critically engages with the often unnuanced academic literature on social support. The research and the typology reveal that the quality of support, as well as the availability of potential or actual support, is not only influenced by socio-economic factors. Rather, the strength of the relationship and the level of intimacy between individuals is an important predictor of support-seeking. As such, this article shows that mechanisms of in/exclusion are highly social, as they entail a diversity of formal and informal support-seeking patterns, which in turn have an important influence on the adoption and use of digital media. The article argues that understanding such mechanisms is rooted in reconciling micro-level interactions to macro-level patterns of inequalities. To show the specificity of social support within digital inequalities research, and to demarcate the concept from definitions of other academic disciplines, the concept of social support for digital inclusion is introduced. It is defined as the aid (emotional, instrumental, and informational) that an individual receives from his/her network in his/her use of digital technologies.
\end{abstract}

\section{Keywords}

age typology; digital divide; digital inclusion; digital inequalities; help-seeking; internet use; social inclusion; social support

\section{Issue}

This article is part of the issue "Digital Inclusion Across the Globe: What Is Being Done to Tackle Digital Inequities?" edited by Bianca C. Reisdorf (University of North Carolina at Charlotte, USA) and Colin Rhinesmith (Simmons University, USA).

(C) 2020 by the authors; licensee Cogitatio (Lisbon, Portugal). This article is licensed under a Creative Commons Attribution 4.0 International License (CC BY).

\section{Introduction}

According to Cobb (1976), social support is information that leads the subject to believe that (s)he is cared for, and that (s)he belongs to a social network of communication. Others define social support either as a flow of emotional concerns, instrumental aid, information or appraisal (House, 1987), or an aggregate of interpersonal interactions facilitating the flow of information between people (Islam et al., 2018). Looking specifically at digital inequalities, recent research shows that so- cial support has an important effect on mechanisms of digital in/exclusion (Mariën \& Baelden, 2016; Mariën \& Prodnik, 2014; Mariën \& van Audenhove, 2010). Indeed, given that not everyone has access to the same level of support, social support is another level at which digital inequalities manifest themselves. However, despite extensive research on digital inequalities and their consequences on mechanisms of in/exclusion (DiMaggio, Hargittai, Neuman, \& Robinson, 2001; Helsper, 2008; van Deursen, 2018; van Deursen, Helsper, Eynon, \& van Dijk, 2017; van Deursen \& van Dijk, 2019), digital inequalities 
studies present two main shortcomings when discussing social support. On the one hand, current research has not yet provided a concise definition of the concept of social support, and without a clear definition, the concept of social support is subject to several interpretations preventing the elaboration of a clear line of research; on the other hand, very little is known about the role of social support in mitigating or intensifying inequalities. In fact, the rare studies conducted on social support focus heavily on quantitative analyses regarding the quality and/or quantity of support (Courtois \& Verdegem, 2016; Helsper \& van Deursen, 2016; van Deursen, Courtois, \& van Dijk, 2014). This article contributes to a better understanding of digital inequalities in two ways: It questions existing classifications by introducing a more complex typology of social support in relation to digital inclusion, and it nuances the causality between socio-economic factors and support. Our research questions are simple: (1) What are the different patterns of social support in relation to digital technologies, and (2) what influence do such patterns have on digital inequalities?

The rest of this article is structured as follows: In Section 2 we engage with the academic work on digital inequalities studies. We highlight the limitations of current research and present our own definition of social support for digital inclusion. In Section 3 we present our methodology. In Section 4 we develop our typology of six patterns of help-seeking and reflect on and confront our findings with existing literature. In Section 5 we reflect on the broader theoretical consequences of our work and consider the implications for digital inclusion policy.

\section{Digital Inequalities Studies and the Concept of Social Support}

Although research on ICT-adoption has shown the importance of social networks as a primary source of support (Bakardjieva, 2005; Brown \& Reingen, 1987; Haythornthwaite, 2002; Stewart, 2007), the concept of social support is only recently being explored within digital inequalities studies. Van Deursen et al. (2014) examined how people deal with inadequate skills levels by identifying the sources and forms of support available to them. They investigated whether internet skills have an effect on the attainment of beneficial outcomes and whether the support sources employed have an influence in moderating these effects. Based on a largescale representative survey, they developed a three-class model delineating the following support patterns: (1) the independents, users with low formal education, who do not need any help; (2) the socially supported, users seeking support from family and friends; and (3) the formal help seekers, users relying heavily on help desk, computer experts, or formal courses.

The results of the survey show that the independents were more likely to be male with higher education levels, while the socially supported were generally female with low levels of education and more often unemployed; the formal help-seekers were constituted of low and mediumeducated users with higher levels of employment than the socially supported. Through this study, van Deursen et al. (2014) show that patterns of support-seeking have a strong influence on the development of digital skills, the benefits one is able to attain from the internet, and on the quality of the support received. However, while the study yielded interesting insights regarding the importance of support, the focus on digital skills somehow obscures the understanding of support-seeking: Why do individuals choose one form of support over another? Do people combine different patterns of support-seeking? Are inadequate skills levels the only factor motivating people to ask for help? Or are there deeper motivations prompting people to ask for help?

Courtois and Verdegem (2016) argue that social support is an indispensable source of social learning. Whereas van Deursen et al. (2014) focused on the link between digital skills and social support, Courtois and Verdegem (2016) consider the composition and socioeconomic background of social support networks and their moderating role in explaining digital inequalities. Based on quantitative analysis, they delineate three main profiles: (1) the domestically networked, users who rely on others (family, friends, etc.) to help out with a problem; (2) the non-domestically networked, users who first ask for support from colleagues and friends; and (3) the self-reliant, users who rarely ask for help but solve problems on their own.

According to this study, the domestically networked were mostly older females from large families and unemployed; the non-domestically networked were younger males, financially at ease, employed, and part of smaller families; the self-reliant were younger users with the tendency to use different languages online. Two important findings can be taken from the study of Courtois and Verdegem (2016). First, those who seek support within their domestic circles are usually from disadvantaged social and economic positions, with low motivation and skills. Second, social embeddedness - that is the extent to which someone is part of a social network-is a key factor to be able to ask and receive help, showing how social and digital factors go hand in hand. While our own research confirms this second conclusion, our findings also show that those who ask for help within their domestic circles are usually those with the most social and economic resources.

Whereas both former studies establish patterns of support seeking, Helsper and van Deursen (2016) focus on quantity and quality of social support and their subsequent influence on digital engagement. To this end, they use different indicators to predict potential and actual use of support, as well as the variety of sources of support used. They distinguish between potential supportsupport people believe they have access to-and actual support-support people have actually used. Their findings show that informal support-also defined as the socially supported (van Deursen et al., 2014) or the 
domestically networked (Courtois \& Verdegem, 2016)was more often used by people with lower levels of digital resources, whereas those with high socio-economic resources turned more easily to formal sources of help (e.g., co-workers, experts). More importantly, this study shows that social support is another level at which digital inequalities manifest themselves: Those who experience the most problems online are the ones with fewer opportunities to receive high-quality support. While our research partially supports this last conclusion, our findings show that not only those with a high level of education benefit from the use of digital technologies but some respondents in other socio-economic groups, in contrast to their peers, are able to take advantage of the use of digital technologies.

To show the specificity of social support within digital inequalities research, and to demarcate the concept from definitions of other academic disciplines, we introduce the concept of social support for digital inclusion. We define it as the aid-emotional, instrumental, and informational-that an individual receives from his/her network in his/her use of digital technologies. We define emotional aid as the support given through appraisal or social companionship during a time of heightened distress caused, for instance, by an individual's fear of technology, while informational aid is a task-oriented form of support (e.g., teaching an individual to use a computer). Informational aid refers to the guidance, advice or feedback an individual receives during the learning process. Social support for digital inclusion points thus to the diverse nature of support networks and highlights the variety of support seeking patterns people use and/or combine, from individuals without access to support networks, to individuals who gain support by emulating others. Henceforth, our definition of digital social support, while built on existing conceptualisations of social support (Cobb, 1976; Islam et al., 2018), asserts the specificity of such a concept for digital inequalities studies by being grounded in the findings of this research.

\section{Methodology and Analysis}

Most studies on social support as a factor in digital inclusion use quantitative methods. This article presents one of the rare qualitative studies in this field. Yet, it is important to note that social support and the patterns of help-seeking were not the initial aims of IDEALiCSetting the Future Scene of Digital Inclusion, a research project in Belgium on which this article is based. The research project focuses on the digitalisation of public and private services in Belgium and its impact on citizens' digital autonomy. However, the discussion on support seeking emerged organically during our conversations with participants. Similarly, the patterns of help-seeking outlined below arose naturally during the qualitative analysis of the in-depth interviews.

Throughout the research, we apply a life-course perspective approach to highlight the complex and changing conceptions of individuals regarding digital technologies. The life course perspective refers to a sequence of activities or events embedded in individuals' lives. This approach aims at mapping, explaining and describing the change in social positions over time (Elder, 1994; Meyer, 2009). This approach states that individuals, at each life stage, are experiencing various life transitions. The notion of 'life stage' points to the roles and social positions an individual occupies over time, whereas 'life transitions' describe the pattern taken by these social positions over time. From this perspective, each transition corresponds to a significant 'step' in life which not only modifies an individual's social status and roles, but also affect their participation in different social spheres.

This article is based on 85 in-depth interviews with respondents distributed across three life stages (see Table 1).

The first life stage (18-30 years old), henceforth called the 1st LS, corresponds to the period in which young adults are building autonomy in all domains of the social life (e.g., employment, relationships, etc.) and are steadily increasing their social, economic and political participation in society.

The second life stage (31-50 years old), henceforth called the 2 nd LS, refers to a period in which individuals are assumed to have developed a certain autonomy and participate fully in society; however, the challenge at this point is to maintain this autonomy and full participation while at the same time managing work, family, and life hazards.

The third life stage (51-70 years old), henceforth called the 3rd LS, can be characterised by the desire to remain active in society while ageing remains an important societal challenge.

Table 1. Overview of the respondents.

\begin{tabular}{|c|c|c|c|c|c|c|c|}
\hline & \multicolumn{2}{|c|}{$18-30 \mathrm{Y} / \mathrm{O}$} & \multicolumn{2}{|c|}{$31-50 \mathrm{Y} / \mathrm{O}$} & \multicolumn{2}{|c|}{$51-70 \mathrm{Y} / \mathrm{O}$} & \multirow[b]{2}{*}{ TOTAL } \\
\hline & $\mathrm{F}$ & M & $\mathrm{F}$ & $M$ & $\mathrm{~F}$ & $M$ & \\
\hline Low education level & 3 & 6 & 2 & 5 & 6 & 5 & 27 \\
\hline Medium education level & 3 & 3 & 5 & 3 & 7 & 4 & 25 \\
\hline High education level & 5 & 4 & 5 & 6 & 4 & 8 & 32 \\
\hline Undetermined & & & 1 & & 1 & & \\
\hline Total F/M & 11 & 13 & 12 & 13 & 18 & 15 & 85 \\
\hline Total & & & & & & & \\
\hline
\end{tabular}


In addition to the life stage perspective, several other criteria were taken into consideration for the selection of respondents:

- The level of education: low education level (LE; maximum middle school diploma); medium education level (ME; maximum high school diploma); and high education level ( $\mathrm{HE}$; minimum bachelor degree);

- The family situation: in couple, living alone, living with parents;

- The presence of children: no children, children living at home, children no longer living at home;

- The social status: employed, retired, student.

The aim of these selection criteria was to have a varied range of profiles over the life trajectories. The sampling was not aimed at statistical representativeness but sought the equal representation of a wide range of individuals. The life course perspective allows us to generate new insights regarding the patterns of help-seeking and social support for digital inclusion (see Table 2). What patterns are present across the three life groups? How do these patterns intersect? Where do they diverge?

Interviews were conducted in Belgium between April-June 2017 and February-June 2018. The respondents were recruited via the networks of the research team and through posts on social media. For groups that were more difficult to reach (e.g., homeless), the research team reached out to its network of grassroots organisations to contact these respondents. Each of the 85 in-depth interviews was conducted face-to-face at the desired location of the respondent (mostly at home). The interviews were transcribed and coded using NVIVO, data analysis software designed for rich text-based data. A codebook was developed in order to ensure the efficient management of large volumes of complex data. The codebook was divided into six different themes: (1) trajectory of life; (2) conditions of access and use; (3) digital engagement; (4) autonomy; (5) outcomes; and (6) perceptions.

The codebook is based on the combination of two methods of exploring data. On the one hand, a deductive or 'top-down' approach was used starting from theories on digital inequalities (Carretero, Vuorikari, \& Punie, 2017; Helsper, 2008, 2016; Helsper \& Eynon, 2013; Helsper, van Deursen, \& Eynon, 2015; Mariën \& Baelden, 2016; van Dijk, 2005; van Deursen, Helsper, Eynon, \& van Dijk, 2017) to explore the data gathered during the in-depth interviews. This theory-driven approach is observable with the fifth theme on outcomes, for instance, referring to the benefits someone is able to draw from his/her engagement online (van Deursen \& Helsper, 2015). The theory-led perspective enabled the research team to identify processes not explicitly identified by the respondents.

On the other hand, an inductive or 'bottom-up' approach was used moving from the observation of concrete realities to the conceptual understanding of the data collected. This 'bottom-up' perspective allowed the research team to 'hear' the voices of the respondents through the analysis. It allowed the construction of theoretical narratives based on the interpretative and subjective nature of interviews. This approached is observ-

Table 2. Overview of the respondents: Additional criteria.

\begin{tabular}{|c|c|c|c|c|c|c|c|}
\hline \multirow[t]{2}{*}{ Family situation } & $\mathrm{F}$ & $\mathrm{M}$ & $\mathrm{F}$ & $M$ & $\mathrm{~F}$ & $M$ & TOTAL \\
\hline & \multicolumn{2}{|c|}{$18-30 \mathrm{Y} / \mathrm{O}$} & \multicolumn{2}{|c|}{$31-50 \mathrm{Y} / \mathrm{O}$} & \multicolumn{2}{|c|}{$51-70 \mathrm{Y} / \mathrm{O}$} & \\
\hline In couple & 5 & 5 & 5 & 8 & 13 & 10 & 46 \\
\hline Living alone & 5 & 4 & 4 & 5 & 8 & 5 & 31 \\
\hline Living with parents & 3 & 3 & 0 & 0 & 0 & 0 & 6 \\
\hline Widow(er) & 0 & 0 & 0 & 0 & 1 & 1 & 2 \\
\hline Total F/M & 13 & 12 & 9 & 13 & 21 & 17 & 85 \\
\hline Total & \multicolumn{2}{|c|}{25} & \multicolumn{2}{|c|}{22} & \multicolumn{2}{|c|}{38} & \\
\hline Children & $\mathrm{F}$ & $M$ & $\mathrm{~F}$ & $M$ & $\mathrm{~F}$ & $M$ & TOTAL \\
\hline No children & 10 & 12 & 5 & 4 & 3 & 3 & 37 \\
\hline Children at home & 2 & 0 & 5 & 9 & 1 & 2 & 19 \\
\hline Children not home & 0 & 0 & 0 & 1 & 16 & 12 & 29 \\
\hline Total M/F & 12 & 12 & 10 & 14 & 20 & 17 & 85 \\
\hline Total & \multicolumn{2}{|c|}{24} & \multicolumn{2}{|c|}{24} & \multicolumn{2}{|c|}{37} & \\
\hline Social status & $\mathrm{F}$ & $\mathrm{M}$ & $\mathrm{F}$ & $M$ & $\mathrm{~F}$ & $\mathrm{M}$ & TOTAL \\
\hline Student & 5 & 3 & 0 & 0 & 0 & 0 & 8 \\
\hline Employed & 6 & 9 & 7 & 7 & 6 & 1 & 36 \\
\hline Unemployed & 1 & 1 & 5 & 6 & 5 & 2 & 20 \\
\hline Retired & 0 & 0 & 0 & 0 & 7 & 14 & 21 \\
\hline Total M/F & 12 & 13 & 12 & 13 & 18 & 17 & 85 \\
\hline Total & \multicolumn{2}{|c|}{25} & \multicolumn{2}{|c|}{25} & \multicolumn{2}{|c|}{35} & \\
\hline
\end{tabular}


able with the sixth theme on perceptions, as individuals' representations of, and relationships with technology, emerged organically during our conversations with the participants.

For the concept of social support for digital inclusion, we distinguished between support online (YouTube tutorials, online forums, etc.), support within close social networks (family, friends, colleagues), support in computer and/or technical centres, and no support-seeking. We further distinguished between those who provide support to family, friends, colleagues, those who give support online (e.g., helping strangers through online forums), and those who do not provide support.

\section{Seeking Help? Towards a Typology of Digital Social Support}

Based on insights from our research, we develop a typology of six patterns of help-seeking and the characteristics associated with them (see Figure 1). The aim of this typology is twofold: (1) to further the debate on social support within digital inequalities studies; and (2) to critically engage with the often unnuanced academic literature on social support. It must be noted that these patterns of support are not mutually exclusive: People combine varied forms of support to meet their needs. However, while support-seeking patterns are not exclusive, the way people switch between patterns of help or the way these patterns change over time become only visible in the long run and would necessitate observing people over the years - a task for further research.

\subsection{The Support-Deprived}

Individuals in the support-deprived category are characterised by their lack of access to social support. They are generally low educated coming from all three life stages. At the social level, their situation is often precari-

\begin{tabular}{|c|c|c|c|}
\hline Type of support & Characteristics & Type of support & Characteristics \\
\hline $\begin{array}{l}\text { Support- } \\
\text { Deprived }\end{array}$ & $\begin{array}{l}\text { - Low level of digital skills and of often in } \\
\text { situations of social precarity and/ or social } \\
\text { exclusion. } \\
\text { - Acknowledge that they need help with } \\
\text { digital technologies but in the incapacity to } \\
\text { find someone to help because of their } \\
\text { situation of exclusion. } \\
\text { - Found within all three life categories } \\
\text { (18-years old; } 31-50 \text { years old; } \\
51-70 \text { years old) }\end{array}$ & $\begin{array}{l}\text { Network- } \\
\text { Supported }\end{array}$ & $\begin{array}{l}\text { - Draw support mainly from close social circle } \\
\text { (family/children/spouses/close friends and/or } \\
\text { coworkers. } \\
\text { - Show the importance of social embdedding: } \\
\text { to be able to draw support, there is a need to } \\
\text { be integrated in a social network. } \\
\text { - Mostly, 2nd life category ( } 31-50 \text { years old) } \\
\text { and 3rd life category ( } 51-70 \text { years old). }\end{array}$ \\
\hline $\begin{array}{l}\text { Community- } \\
\text { Supported }\end{array}$ & $\begin{array}{l}\text { - Almost all sources of support come from } \\
\text { computer room and/or computer classes. } \\
\text { - Computer room/classes seen as: } \\
\text { - a way out of potential exclusion, both at } \\
\text { the social and digital level } \\
\text { - a way to become more independent (no } \\
\text { longer depends on children for support) } \\
\text { - Mostly respondents from 3rd life category } \\
\text { (51-70 years old) }\end{array}$ & $\begin{array}{l}\text { Vicarious } \\
\text { Learners }\end{array}$ & $\begin{array}{l}\text { - Do not explicitly ask for support but learn by } \\
\text { emulating others. } \\
\text { - Rely on watching friends' and family's use of } \\
\text { digital media and from then onwards start } \\
\text { learning by doing. } \\
\text { - Mostly respondents from the 1st life category } \\
\text { (18-30 years old). }\end{array}$ \\
\hline $\begin{array}{l}\text { Supported } \\
\text { Throught } \\
\text { Substitution }\end{array}$ & $\begin{array}{l}\text { - Do not directly engage with digital media but } \\
\text { ask someone in their close social circle } \\
\text { (generally family members) to accomplish a } \\
\text { specific task for them (e.g. send an email) } \\
\text { - Spotted with older couples where one spouse } \\
\text { either has more skills than the other or when } \\
\text { one spouse does not want to use digital media. } \\
\text { - To be distinguished between a) supported } \\
\text { with low digital skills, and b) supported with } \\
\text { low motivation. } \\
\text { - Mostly respondents from late 2nd life category } \\
\text { (41-50 years old) and 3rd life category } \\
51-70 \text { years old) }\end{array}$ & $\begin{array}{c}\text { Self } \\
\text { Supported }\end{array}$ & $\begin{array}{l}\text { - Do not seek support from the domestic sphere } \\
\text { but are a great source of support for others } \\
\text { (mostly domestic circle). } \\
\text { - Reveal high levels of digital skills and digital } \\
\text { fluidity. Are more likely to stretch out of their } \\
\text { comfort zone to learn new things. When help } \\
\text { is needed, they look for solutions online and } \\
\text { learn by doing. } \\
\text { - Mostly respondents from the late } 1 \text { st life } \\
\text { category and early } 2 \text { nd life category (between, } \\
25 \text { and } 45 \text { years old). Mostly male and highly } \\
\text { educated. }\end{array}$ \\
\hline
\end{tabular}

Figure 1. Patterns of social support. 
ous (unemployed, retired, chronically ill, etc.): They possess a limited-often inexistent-social network. At the digital level, their low economic resources prevent them from having access to and/or owning quality digital tools. As a result, the support-deprived are often individuals with very low digital skills. This already precarious situation is further aggravated by the fact that they do not have access to help. Indeed, while most of the respondents within this cluster acknowledge that they need help (e.g., to send an email), they also recognise their inability to ask for support when they need it. This category of respondents has not, to our knowledge, been identified in current research on social support. Supportdeprived individuals lack emotional, as well as informational and instrumental aid:

Interviewer: When you are confronted with problems with your smartphone, do you ask for help?

Respondent: Most of the times I just give up. When I find myself in difficulties and I don't know how to use it, the problem is I don't have anyone near me to show me how to use my smartphone or do this or that operation with it.

Interviewer: So, there are moments where you really don't know what to do and where you just give up?

Respondent: Yes, it happens. And since I do not have a computer it is really not easy. (Female, 28,1 st LS, LE, living with her parents, no children, student)

Respondent: I would like to be able to use it [technology in general], yes, because otherwise you are no longer part of society. It evolves so fast that it becomes impossible to follow what is happening. You are almost obliged to have this technology. And you constantly have this feeling that, yes, it is needed but [pause] if you don't have this technology you are completely left out of everything. (Female, 53, 3rd LS, LE, living alone, no children at home, unemployed)

For this category of respondents, the feeling of exclusion as well as the awareness of being pushed to the margins of society is acute. In addition, the social pressures and the sentiment of being compelled to engage with the digital is a recurrent theme within this category. On the one hand, digital evolutions occur at a rate they have difficulty following; on the other hand, the increasing digitisation of society presses them toward even more digital solutions, regardless of their inability to keep up with technological evolutions.

This confirms the findings of Courtois and Verdegem (2016) and Mariën (2016) on the impact of social embeddedness on digital engagement. The quotes from the support-deprived show how social and digital factors play a role in mechanisms of in/exclusion. Indeed, respondents in this category often expressed a sense of powerlessness. The challenges they face at the digital level impede their societal participation. It also partially confirms the findings of Helsper and van Deursen (2016) according to which those most in need of help are the ones with fewer opportunities to access highquality support. In that sense, social support is indeed another level at which inequalities, both social and digital, are manifested.

\subsection{The Community-Supported}

The community-supported category refers to the individuals whose only source of support comes from computer classes, computer training organised by state/municipality-funded organisations, or digital inclusion intermediaries. In that sense, they resemble the formal help seekers of van Deursen et al. (2014), as they rely on formal help as their main source of support. However, our study shows that, for this category of support seekers, age is a more discriminant factor than education: The technically supported in this research are mainly found among respondents from the 3rd LS (51-70 years of age), with gender and education levels all taken into account. For this cluster, instrumental or task-oriented, and informational aid are important. These individuals usually display low levels of digital skills which can be explained by the fact that digital technologies are relatively new for this generation:

Respondent: Yes, so it is not always easy. I am sixtysix and I think that for older people it is a real performance to come here to follow computer classes. To be so willing to work with the computer, I think, it is unique actually. Because you should not underestimate the difficulty, all this is quite new for our generation. (Female, 66, 3rd LS, LE, in a couple, no children at home, retired)

Despite low levels of skills, the community-supported show high motivation to learn. This motivation is expressed in two ways: On the one hand, the decision to start computer classes is motivated for some respondents by the fact that their low digital skills expose them to potential exclusion. As told by one of the participants (male, 60, 3rd LS, LE, living alone, no children, unemployed), the fear of becoming digitally illiterate, associated with a precarious socio-economic situation and the urgency to find employment, motivated his decision to start learning to use digital technologies. Indeed, due to a severe back injury, this respondent had to leave his construction job to find a less manual form of labour. This meant automatically having to engage with digital technologies on a regular basis. Another respondent says the following:

You come to a point where you say: You really can't do without digital media. And that is...especially, when you go to the GB [supermarket], there are papers 
sometimes, but when you don't have your card with you then you have to go through the computer. Now that has been adjusted, now they do it themselves since a few days ago, but before you had to log in and do that alone. Then I think: I have to know more about it. Because you are really right there, like a layman, and you do not know how to push or pull a button. And that helped me, also those lessons here at the municipality. (Female, 66, 3rd LS, ME, in a couple, no children at home, retired)

On the other side, some respondents see in the computer classes the opportunity to become more autonomous in their digital experience. This category of respondents is generally reliant on the support of their children and they are motivated to learn new skills because they desire to be independent:

Respondent: In the beginning, I was about forty, and they, my children, they were about fifteen or something....and yes, having to admit that you cannot do that, alas, that is hard. I can't do everything here.....Bwa, it's not that bad. But, that's true, that's true: I used to be the one who could do anything here and, in those days, I had to ask my child. And so I am not used to that. (Male, 63, 3rd LS, HE, in couple, children at home, retired)

As shown by Kiesler, Zdaniuk, Lundmark, and Kraut (2000, p. 345), the dynamics of help at home can become problematic, especially when "children's technical expertise shifts intellectual expertise in the family." Henceforth, for this category of respondents, finding help in computer centres is crucial for the development of their digital skills and autonomy as it allows them to gradually gain independence from their close social networks.

This cluster deviates from categories of support patterns as defined in academic literature (Courtois \& Verdegem, 2016; van Deursen et al., 2014). Help-seeking is not only activated when individuals are confronted with problems. As demonstrated by the communitysupported, social support is at times a pre-emptive measure undertaken to achieve a desired need-finding a job or becoming more independent. Once again, the social context of the individual is crucial to explain the deeper motivations stimulating people to seek support.

\subsection{The Supported through Substitution}

Selwyn, Johnson, Nemorin, and Knight (2016) discuss the role of proxy users and their use of technology on behalf of others. We propose the supported through substitution category, which is slightly different. It refers to those users who use technology 'through' others and consists of individuals who refuse or are unable to use and/or access digital technologies. While proxy users accomplish tasks for others, supported through substitution access and/or use technology through others. In other words, supported through substitution access and/or use technology through proxy users by asking them to perform the tasks they need: printing a document, sending an email, paying taxes, etc. Hence, this category is relevant as, contrary to the proxy users who accomplish tasks on behalf of others, the supported through substitution allow us to understand the motivations of those who make use of proxy users. For this cluster, proxy users constitute a source of emotional aid, supporting them during a time of heightened stress (e.g., anxiety at the thought of using a computer), and of instrumental aid or task-oriented help. They do not resemble any existing category as, to our knowledge, this type of user has not been classified within current research on social support.

Far from being a homogenous group, their levels of education allow us to distinguish between: (1) those who have low digital skills and are subject to buttonanxiety; and (2) those who are not motivated to use digital technologies.

\subsubsection{The Supported through Substitution with Low Digital Skills}

This category consists of individuals with low to middle education levels and found mostly within late 2nd LS (40-51 years of age) and the 3rd LS (51-70 years of age). They heavily rely on their social circle to engage with digital media:

Respondent: I don't know my email address by heart. So now I have written it on a piece of paper, and I keep it with me. Because now I know what the consequences will be if I ever lose it again. So, I ask a good friend of mine to regularly check my mailbox with me, or I ask him to do it for me, like homework [laughs] and to check if there is something and send me an SMS if there is. It is so embarrassing. I am ashamed to find myself in this situation. It feels like I am illiterate. (Male, 49 , 2nd LS, LE, living alone, no children, unemployed)

For the respondents of this category, their use of a proxy is mainly motivated by a fear of digital technologies. This fear of technology is accentuated by low levels of selfconfidence, both regarding their social position and their digital capacities. Our research shows that this fear of technology is often linked to negative experiences with the digital: these respondents often have the feeling of being 'punished' for not using digital media.

Much like the support-deprived, this cluster shows the importance of social embedding. More importantly, it shows that despite the availability of support, society plays a great role in individuals' use and adoption of technology. Our findings indicate that these commonplace discourtesies - such as being fined for not using an online platform-reinforce individuals' negative perceptions of digital media and hamper the development of their digital autonomy. In that sense, society puts strong expectations upon such individuals without giving them 
the tools and means to answer these expectations.

\subsubsection{The Supported through Substitution with Low Motivation}

The second type of supported through substitution can be found within close family circles, and more precisely with older couples (3rd LS, 51-70 years of age). In these couples, one spouse-in our study generally the woman-has more skills than the other who refuses to engage with technologies. Respondents in this group correspond to what Mariën (2016) calls the "digitally selfexcluded": high- to middle-educated individuals, with a rich social network, access to digital technologies but who choose not to engage with the digital because of their lack of motivation. Commonly, lack of time and retirement are put forward as reasons for disengagement:

Respondent: [Talking about his wife] I do not have anything against the automatization, or the fact that everything now happens digitally. I know how and what to do. But as I said, I am retired now; I was first on sick leave and then went into retirement. I could still type one or two letters with the computer but in the meantime, I have an amazing secretary [laughs] and I just let her take care of everything. She does everything I ask, for now at least [laughs]. (Male, 68, 3rd LS, $\mathrm{HE}$, in a couple, no children at home, retired)

This cluster is interesting as it demonstrates that motivation and social perception of technology, more than socio-economic indicators, influence the pattern of helpseeking. It also shows that the lack of motivation is not solely linked to negative attitudes (Reisdorf, 2011); rather, some individuals do not see the value of engaging with technologies (Helsper, 2016). Yet, both types of support raise a series of questions: What happens when the proxy-user disappears? Should we help them develop their own digital skills, or find ways to motivate their engagement with technologies?

\subsection{The Network-Supported}

Network support is the most common form of support within our 85 respondents. Respondents from this cluster are usually middle- to highly educated, from the 2 nd LS and 3rd LS. They mainly draw support from their close social network: at home with spouses and/or children, and at work with colleagues. The key concept to understand this type of support is the notion of homophily (McPherson, Smith-Lovin, \& Cook, 2001). The concept of homophily refers to the idea that "contact between similar people occurs at a higher rate than contact between dissimilar people" (McPherson et al., 2001, p. 416). In other words, people tend to build their social networks around and with people who are most like themselves in terms of personal characteristics. As McPherson et al. (2001, p. 415) put it: "Similarity breeds connection."
This cluster resembles the socially-supported of van Deursen et al. (2014) and the domestically-networked of Courtois and Verdegem (2016) as they make significant use of family and friends as sources of support. However, contrary to most research on social support (Courtois \& Verdegem, 2016; van Deursen et al., 2014), we place the help received from co-workers at the same level as the help received within the family. We argue that the common denominator between these seemingly different sources of help resides in the strength of the tie uniting individuals. In fact, our research shows that individuals will only ask for help from close co-workers they feel they can trust and consider part of their close social networks. Moreover, individuals asking for help at work usually rely on friends and family when the support from co-workers is unavailable. In comparison to other categories, this group is able to rely on a large network of family, friends, and co-workers and is capable of combining different forms of help-informational, instrumental, and emotional:

Respondent: Yes, looking for help....If I need help with software or something like that, I will more easily ask a colleague I know well, like: Hey! Do you know how this and that works? But yeah, for the rest I just ask my girlfriend sometimes, but I think that's just it. (Male, 48, 2nd LS, HE, in a couple, children at home, employed)

Respondent: Oh, usually I ask Natasha or Kristof [coworkers], Kristof most of the time because he is good with this sort of stuff and he knows what to do. So, I go to them with my problem and I just ask: Hey, can you help me find a solution? And in last resort, I go to the IT-helpdesk of the bank, but they are almost all external to the bank, so I don't do it often. (Female, 57, 3rd LS, HE, in a couple, no children at home, employed)

As observed by Courtois and Verdegem (2016), networksupported in the context of the workplace are generally financially secure with stable employment. In line with van Deursen et al. (2014) and Stewart (2007), this cluster reiterates the crucial role of the workplace as a locus of help. This cluster also demonstrates how personal offline resources can be translated into the digital world with the appropriate support, and the importance of social capital. The concept of homophily associated to the concept of social support for digital inclusion shows partially how the rich-in terms of social, cultural, and economic resources-keep getting richer by accumulating and translating social resources into digital resources. In fact, the aforementioned respondent acknowledges that, as a result of the high-quality support from her co-workers, she noticed that her use of technology was becoming more intuitive. She still faces specific difficulties but manages more easily to solve problems on her own this cluster makes evident that social support is another level at which mechanisms of in/exclusion are per- 
vasive (Helsper \& van Deursen, 2016). Unlike the supportdeprived individuals who lack the social embedding necessary to ask and receive help, or the supported through substitution with right resources but the low motivation, the network-supported, because of their deep social inclusion, are able to face specific digital challenges by asking for help.

At home, the network-supported tend to draw support mostly from their children and spouses. Contrary to the studies of Courtois and Verdegem (2016), or Helsper and van Deursen (2016), our research shows that those relying on family and friends do not necessarily come from a disadvantaged position, nor do they exhibit low digital skills. Rather, specifically for this research, our findings suggest that those relying on family and friends are usually respondents with a mid to high education level, financially secure and generally employed. Moreover, network-supported in the family context do not typically score low in terms of digital skills; instead, they make use of their social network to solve very specific problems:

Respondent: No, I will first try to do things by myself, try to discover things by myself and test things for a while. Sometimes it works well and other times I need help with something in particular. So, if I try and it does not work and I see that it is taking me too much time, I just ask my younger son, yes, I still have one son at home. He studies at the VUB [university], bioengineer. So, when he is home, I just ask him, otherwise, there is always one of them [his sons] that I can ask for help. (Male, 66, 3rd LS, HE, widower, children at home, retired)

Respondent: My husband used to pay all our bills and when he died, I stayed almost one year going all the time to the bank to do my bank transfers. Everyone was always telling me how easy it was to do everything online, but no one ever showed me. And one day, my daughter came home, and she sat for an hour with me and showed me how to do it. Now I feel almost stupid when I think of how much difficulty I had before. (Female, 68, 3rd LS, ME, widow, no children at home, retired)

Network-supported in the context of family support the findings of several studies (Bakardjieva, 2005; Chu, 2010; Correa, Straubhaar, Chen, \& Spence, 2013; Stewart, 2007), emphasising the role of the family as source of support, and the importance of intergenerational exchanges of knowledge (Dolničar, Hrast, Vehovar, \& Petrovčič, 2013). This category also raises questions regarding the sustainability of such a form of support. For some respondents, learning in a family context is perceived as frustrating as family members-most often children-do not always have the time or the motivation to help. This frustration often results in a strong need to be self-sufficient in their use of technology and a desire to be independent of their children's help. As such, network-supported in the context of the family are also very often the community-supported:

Interviewer: Could you give a specific example of your daughter not wanting to help?

Respondent: Let's say that something happens. Something pops up on the bottom of my computer or my mailboxes. I'm always afraid to open it because I don't know what might happen if I click on it. My daughter just tells me 'When you don't know don't touch' but...I don't want to be dependent anymore. That's the reason why I go to the EPN [public computer centre] with my computer to ask questions. (Male, 46, 2nd LS, ME, in a couple, children at home, employed)

\subsection{The Vicarious Learners}

The vicarious learners are mostly found in the 1st LS (18-30 years of age), and at the beginning of the 2nd LS (31-33 years of age), middle- to highly educated. Vicarious learners express some of the characteristics of the network-supported as they rely extensively on their close social networks in order to engage with digital technologies. Nonetheless, they distinguish themselves from other patterns of support, as they gain confidence from watching the digital uses of friends and family members before deciding to use the technology themselves. Put differently, contrary to the supported through substitution, who access technologies through others, the vicarious learners learn to use technologies through others. In that sense, social support for digital inclusion takes mainly the form of informational aid for this cluster: Close social networks act as "local institutions" or "local experts" (Stewart, 2007) whose opinions and information are highly valued by the vicarious learners:

Respondent: My mom works at Belfius [Belgian Bank], and at first I thought, yes...but such an app on your mobile with your bank details, I don't know...because with your money...imagine if someone steals your phone or imagine you are hacked, then that person can get all your money. But then my mama told me no, no, [that] it is very safe, and you have to do that and that and that. So actually, I am always afraid of something happening with my cell phone, but then if there is someone who can convince me that it is not true, then I have no problem, then it works for me. (Female, 25 , 1st LS, HE, in a couple, no children, employed)

Respondent: So, yes, I don't have a particular interest in this or that. I mean, I'm not going to go and download an app just to see how it works, no, no. For example, when I hear my friends say, oh...that, for instance, now that Payconiq [electronic payment] app is booming, and that is usually how it happens, so If I hear from friends, say: Oh, J., the app is abso- 
lutely great! Yes, then I would probably try that in the long term, yes, yes. But testing things in itself is not in me. (Male, 33, 2nd LS, ME, living alone, children at home, unemployed)

Once the vicarious learners are convinced of the validity or usefulness of digital tools, they start discovering the digital by themselves through trial and error. They remain a strong basis of support for the less-skilled members of their social networks and are often the source of help of the network-supported. The question this cluster raises is whether this self-learning approach is beneficial for the development of their digital skills. As noted by van Deursen and van Dijk (2010), while people may learn effectively by trial and error, they also tend to reproduce the same mistakes online once they achieve the goals they have in mind. In that sense, contrary to the following pattern of support, which shows high levels of skills from the beginning, vicarious learners run the risk of building questionable and weak skills when learning by doing.

\subsection{The Self-Supported}

Self-supported learners are the least common type. They can be compared to what van Deursen et al. (2014) called "the independents," and to what Courtois and Verdegem (2016) call "the self-reliant." The self-supported do not ask for help, although they possess the network to do so. Instead, they seem to learn intuitively, revealing high levels of digital skills and digital autonomy. The selfsupported are generally male, highly educated, aged between 25 and 45 years old and working closely with digital media. In general, they have high-quality access and equipment. They tend to move out of their comfort zone to learn new things and are confident about their skills. While the vicarious learners also learn by doing, the selfsupported differ from this typology in the sense that they rarely wait for a local expert's approval before trying new technology, and they exhibit high levels of digital skills form the start:

Respondent: I will easily try something out if it is new or if I hear something from friends, or I see someone with it and...it seems cool. Sometimes I test also to see if that suits me and if it fits in with my way of working. (Male, 35, 2nd LS, HE, in a couple, children at home, employed)

Respondent: Photoshop, for example, is something that I like, it is a hobby I learned by myself years ago. And there are always new versions and when I have to make something with Photoshop sometimes it's true, I don't know where to start so I just browse tutorials on YouTube. The same for my music software: I can go on the website of the software or look on forums what other users are saying, but...yes, I don't see the need to ask others because I know how to look for stuff by myself. (Male, 44, 2nd LS, HE, in a couple, children at home, employed)

Self-supported learners constitute a prominent source of support for their social network. They form the support basis for network-supported and vicarious learners: They are often the co-workers, the digital experts giving inhouse training, the children helping the parents or the local experts of the vicarious learners:

Interviewer: And can you recount a moment where you provided help to someone else?

Respondent: Yes, definitely my grandparents: helping them with their computer, printing stuff on one page instead of two, helping with emails, downloading stuff and helping them find what they have downloaded, installing Dropbox on their computers and explaining to them how it works. Yes, actually helping a lot in the family with like real concrete stuff. (Male, 25, 1st LS, $\mathrm{HE}$, living with parents, no children, employed)

The concept of homophily again plays a significant role, as high-quality support tends to be given within highly homogenous social networks. As shown by Yuan and Gay (2006), homophily has a strong influence on the creation of learning communities. As the likelihood of social interactions increases among similar people, so does the formation of network ties when it comes to learning communities. By assisting their social environment, selfsupported act as gatekeepers in the distribution of knowledge, thus enabling the people in their environment to develop their digital skills and autonomy. Policy interventions should consider this type of support as a pathway to the digital inclusion of those lacking the resources to ask for and receive help.

\section{Conclusion: Digital Social Support and the Question of Inclusion}

As mentioned in Section 4-in which we have described our typology-we have constantly reflected on and confronted our findings with existing academic literature. We will not repeat this here. In this section we explore the broader theoretical implications of our work and point to consequences for policy. It is clear by now that digital inclusion is not just a technological issue; rather it entails a variety of formal and informal sources of help enhancing or constraining access to and use of technologies.

Our concept of social support for digital inclusion allows us to rethink digital inclusion in two main ways. At a theoretical level, the concept of social support for digital inclusion reveals how individuals develop various ways of coping with learning in a society in constant change. Indeed, rapid technological evolutions are progressively transforming all realms of society, requiring individuals to learn and/or update their skills at a faster rate than 
before (Asmar, van Audenhove, \& Mariën, in press). The role of social support for digital inclusion in coping with fast-paced learning is evident in two ways:

- Support networks are not only invoked in time of heightened stress or when individuals are faced with difficulties. As highlighted by the communitysupported, some respondents reached out to their support networks in a pre-emptive manner. In fact, some respondents were acutely aware that certain life transitions were threatening their digital inclusion in the long run (e.g., having to find a new job when having low digital skills). As such, these respondents reached to their support networks at a very early stage of their learning process to avert the consequences of potential exclusion;

- Social support is not only invoked by individuals with low digital skills. As demonstrated by the network-supported, the vicarious learners, and to some extent, the self-supported, social support is often used by individuals seeking to resolve very specific problems. To do so, they resort to distinct persons in their networks (e.g., co-worker) and once their problems are solved, they are able to resume their learning process.

Highlighting these ways of coping with learning in a fastpaced society allows demonstrating first the agency of our respondents in choosing which moments are the most beneficial to make use of their support networks. Second, this agentic behaviour shows that respondents are highly aware of the potential outcomes attached to the use of their networks (e.g., better skills to find a better job). However, we contend that these outcomes still have to be explored and better understood by digital inclusion researchers. We are confident that such a shift would benefit digital inclusion researchers by opening up a research agenda that is less focused on socio-economic indicators as factors of social support, and more centred on understanding the different outcomes people are able to gain from the use of support networks.

Concerning inclusion initiatives and policies, we argue against traditional approaches on digital inequalities considering being digitally included as an individual responsibility (Mariën, Heyman, Salemink, \& van Audenhove, 2016; Wauters, Mariën, \& van Audenhove, in press). As outlined in this contribution, the individuals who were able to access and benefit the most from social support-supported through substitution with low motivation, network-supported, vicarious learners, selfsupported-were the ones included in dense social networks. Indeed, contrary to most quantitative studies on social support (Courtois \& Verdegem, 2016; van Deursen et al., 2014), our research shows that those with high education levels are not always the only ones on the right side of the digital divide - that is to say the ones able to benefit the most from their use of digital technologies in their everyday life (Buente \& Robbin, 2008). Our find- ings reveal that some lower-educated respondents, contrary to their peers, find themselves on the right side of the divide as well. Despite their difficulties, social and/or digital, they show high interest and motivation to engage with digital technologies. This positive disposition is translated in conscious efforts to develop their skills through computer classes, by asking for help or through trial and error. Moreover, quantitative studies on social support tend to rely heavily on socio-economic and sociocultural factors as indicators of the quality or availability of support. Yet, our findings suggest that the quality, as well as the availability of potential or actual support, is also influenced by the strength of the relationships between individuals. Put differently, intimacy is an important predictor of support that needs to be taken into account in typologies of support-seeking. As such, it is important at the policy and community level to recognise these social interactions in which digital inclusion can flourish: the learning communities in computer classes, in the workplace, within the familial circle.

\section{Conflict of Interests}

The authors declare no conflict of interests.

\section{References}

Asmar, A., van Audenhove, L., \& Mariën, I. (in press). Setting the future scene of inclusion: A qualitative analysis beyond the life course (Research Report D.2.2). Brussels: Belspo.

Bakardjieva, M. (2005). Internet society: The Internet in the everyday life. Thousand Oaks, CA: Sage.

Brown, J., \& Reingen, P. H. (1987). Social ties and word of mouth rereferral behaviour. Journal of Consumer Research, 14(3), 350-361.

Buente, W., \& Robbin, A. (2008). Trends in internet information behavior 2000-2004. Journal of the American Society for Information Science and Technology, 59(11), 1743-1760.

Carretero, S., Vuorikari, R., \& Punie, Y. (2017). Digicomp 2.1: The digital competence framework for citizens with eight proficiency levels and examples of use (Report No. JRC106281). Seville: Joint Research Center.

Chu, R. J. C. (2010). How family support and internet selfefficacy influence the effects of e-learning among higher aged adults: Analyses of gender and age differences. Computers \& Education, 55, 255-264.

Cobb, S. (1976). Social support as moderator of life stress. Psychosomatic Medicine, 35(8), 300-314.

Correa, T., Straubhaar, D., Chen, W., \& Spence, J. (2013). Brokering new technologies: The role of children in their parents' usage of the internet. New Media \& Society, 17(4), 323-351.

Courtois, C., \& Verdegem, P. (2016). With a little help from my friends: An analysis of the role of social support in digital inequalities. New Media \& Society, 18(8), 1508-1527. 
DiMaggio, P., Hargittai, E., Neuman, W. R., \& Robinson, J. P. (2001). Social implications of the internet. Annual Review of Sociology, 27(1), 307-336.

Dolničar, V., Hrast, M. F., Vehovar, V., \& Petrovčič, A. (2013). Digital inequality and intergenerational solidarity: The role of social support in proxy internet use. AolR: Selected Papers of Internet Research, 3, 1-4.

Elder, G. (1994). Time, human agency and social change: Perspectives on the life course. Social Psychology Quarterly, 57(1), 4-5.

Haythornthwaite, C. (2002). Strong, weak, latent ties and the impact of new media. The Information Society, 18(5), 385-401.

Helsper, E. (2008). Digital inclusion: An analysis of social disadvantage and the information society. London: Department for Communities and Local Government.

Helsper, E. (2016). The social relativity of digital exclusion: Applying relative deprivation theory to digital inequalities. Communication Theory, 27(3), 223-242.

Helsper, E., \& Eynon, R. (2013). Distinct skill pathways to digital engagement. European Journal of Communication, 28(6), 696-713.

Helsper, E., van Deursen, A., \& Eynon, R. (2015). Tangible outcomes of internet use: From digital skills to tangible outcomes (Project report). London: DiSTO. Retrieved from https://www.oii.ox.ac.uk/ research/projects/measures-and-models-ofinternet-use?people

Helsper, E., \& van Deursen, A. (2016). Do the rich get digitally richer? Quantity and quality of support for digital engagement. Information, Communication \& Society, 20(5), 700-714.

House, J. (1987). Social support and social structure. Sociological Forum, 2(1), 135-146.

Islam, S., Malik, I. M., Hussain, S., Thursamy, R., Shujahat, M., \& Sajjad, M. (2018). Motives of excessive internet use and its impact on the academic performance of business students in Pakistan. Journal of Substance Use, 23(3), 254-261.

Kiesler, S., Zdaniuk, B., Lundmark, V., \& Kraut, R. (2000). Troubles with the internet, the dynamics of help of at home. International Journal of Human-Computer Interaction, 15, 323-351.

Mariën, I., \& Baelden, D. (2016). 8 profielen van digital ongelijkhedenen [8 profiles of digital inequalities] (Research Report). Brussels: Belspo.

Mariën, I., Heyman, R., Salemink, K., \& van Audenhove, L. (2016). Digital by default. Consequences, causalities and coping strategies. In J. Servaes \& T. Oyedemi (Eds.), Social inequalities, media and communication: Theory and roots (pp. 167-188). Lanham, MD: Rowman \& Littlefield.

Mariën, I., \& Prodnik, J. (2014) Digital inclusion and user (dis)empowerment: A critical perspective. Info, 16(6), 35-47.

Mariën, I., \& van Audenhove, L. (2010). Embedding digital inclusion initiatives in people's reality: The role of social network in tackling the digital divide. Paper presented at DIGITAS Conference, Sibiu, Romania.

McPherson, M., Smith-Lovin, L., \& Cook, J. M. (2001). Birds of a feather: Homophily in social networks. Annual Review of Sociology, 27(1), 415-444.

Meyer, K. (2009). New directions on the life course research. Annual Review of Sociology, 35, 413-433.

Reisdorf, B. (2011). Non-adoption of the internet in Great Britain and Sweden. Information, Communication \& Society, 14(3), 400-420.

Selwyn, N., Johnson, N., Nemorin, S., \& Knight, E. (2016). Going online on behalf of others: An investigation of 'proxy' internet consumers. Sydney: Australian Communications Consumer Action Network.

Stewart, J. (2007). Local experts in the domestication of information and communication technologies. Information, Communication \& Society, 10(4), 547-569.

van Deursen, A. (2018). Digitale Ongelijkheden in Nederland Anno 2018 [Digital inequalities in Holland, year 2018. (Research Report). Twente: Universiteit Twente.

van Deursen, A., Courtois, C., \& van Dijk, J. (2014). Internet skills, sources of support and benefits of internet use. International Journal of Human-Computer Interaction, 30(4), 278-290.

van Deursen, A., \& Helsper, E. (2015). The third level digital divide: Who benefits most from being online? Communication and Information Technologies Annual, 10, 29-52.

van Deursen, A., Helsper, E., Eynon,R., \& van Dijk, J. A. (2017). The compoundness and sequentiality of digital inequality. International Journal of Communication, 11, 452-473.

van Deursen, A., \& van Dijk, J. A. (2010). Measuring internet skills. International Journal of Human-Computer Interaction, 26(10), 891-916.

van Deursen, A., \& van Dijk, J. (2019). The first-level digital divide shifts from inequalities in physical access to inequalities in material access. New Media \& Society, 21(2), 354-375.

van Dijk, J. (2005). The deepening divide: Inequality in the information society. Thousand Oaks, CA: Sage.

Wauters, C., Mariën, I., \& van Audenhove, L. (in press). Digital public services: A threat to citizens' rights? (Research Report D4.2). Brussels: Belspo.

Yuan, C., \& Gay, G. (2006). Homophily of network ties and bonding and bridging social capital in computermediated distributed teams. Journal of ComputerMediated Communication, 11(4), 1062-1084. 


\section{About the Authors}

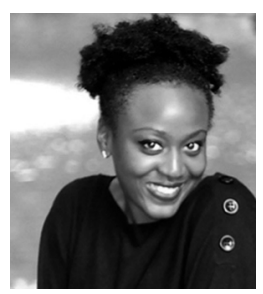

Axelle Asmar is a Teaching Assistant and PhD Researcher within the Department of Communication Studies at Vrije Universiteit Brussel. Her interests revolve around understanding the co-action of social and digital inclusion, as well as studying the societal impacts of digital platforms on citizens' lives: How do platforms as curators of culture reproduce inequalities? How do they generate new tools for citizens' empowerment? How do they generate new vulnerabilities?

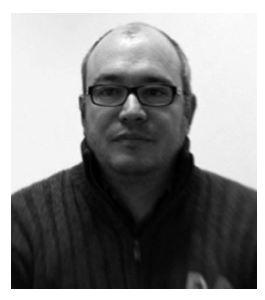

Leo van Audenhove is Professor and Head of Department at the Department of Communication Studies at Vrije Universiteit Brussel. He is a researcher at IMEC-SMIT-VUB and extra-ordinary professor at the University of Western Cape. In 2013, he was instrumental in setting up the Knowledge Center for Media Literacy in Flanders, of which he subsequently became the director. The centre was established by the government as an independent centre to promote media literacy in Flanders. His research focuses on Internet governance, media literacy, e-inclusion and ICT for development.

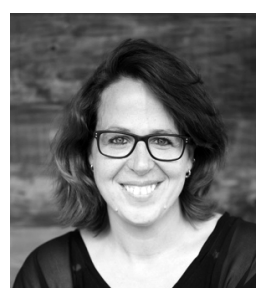

Ilse Mariën joined the IMEC-SMIT-VUB research centre in 2007, where she has worked on several research projects related to the social implications and policy aspects of digital media. Over the years Ilse has built a great deal of expertise on e-inclusion theories and policies, doing research with vulnerable groups and groups at risk of digital and social exclusion, and participatory and action-oriented research methods. Currently, she is leading the Databuzz project that focuses on the deployment of data literacy training in schools and adult education facilities. 